\title{
Anterior cervical discectomy and fusion versus anterior cervical corpectomy and fusion in the treatment of multilevel cervical spondylotic myelopathy: systematic review and a meta-analysis
}

\author{
This article was published in the following Dove Press journal: \\ Therapeutics and Clinical Risk Management \\ 29 January 2015 \\ Number of times this article has been viewed
}

\author{
Zhi-qiang Wen' \\ jing-yu $\mathrm{Du}^{\prime}$ \\ Zhi-heng Ling' \\ Hai-dong $X^{2}{ }^{2}$ \\ Xiang-jin Lin' \\ 'Department of Orthopaedics, \\ The First Affiliated Hospital, \\ College of Medicine, Zhejiang \\ University, Hangzhou, Zhejiang, \\ ${ }^{2}$ Department of Spine Surgery, \\ jinling Hospital, School of Medicine, \\ Nanjing University, Nanjing, People's \\ Republic of China
}

Correspondence: Xiang-Jin Lin Department of Orthopaedics, The First Affiliated Hospital, College of Medicine, Zhejiang University, 79 Qinchun Road, Hangzhou, Zhejiang 310003, People's Republic of China Tel +86 57I 87236666 Email xiangjinlinmd@I63.com
Background: To date, the decision to treat multilevel cervical spondylotic myelopathy (CSM) with anterior cervical discectomy and fusion (ACDF) or anterior cervical corpectomy and fusion (ACCF) remains controversial. Therefore, we conducted a meta-analysis to quantitatively determine the efficacy of ACDF and ACCF in the treatment of multilevel CSM.

Methods: We searched several databases for related research articles published in English or Chinese. We extracted and assessed the data independently. We determined the pooled data, data heterogeneity, and overall effect, respectively.

Results: We identified 15 eligible studies with 1,368 patients. We found that blood loss and numbers of complications during surgery in ACDF were significantly less that in ACCF; however, other clinical outcomes, such as operation time, bone fusion failure, post Japanese Orthopedic Association scores, recovery rates, and visual analog scale scores between ACDF and ACCF with multilevel CSM were not significantly different.

Conclusion: Our results strongly suggest that surgical treatments of multilevel CSM are similar in terms of most clinical outcomes using ACDF or ACCF.

Keyword: meta-analysis, therapy, anterior cervical discectomy and fusion, anterior cervical corpectomy and fusion, cervical spondylotic myelopathy

\section{Introduction}

Cervical spondylotic myelopathy (CSM) is a common spinal disease caused by narrowing of the cervical spinal canal as a result of degenerative and congenital changes, and leads to significant neurological disability. ${ }^{1-3}$ Except major cause of spinal degeneration, cervical congenital malformations that result in progressive scoliosis, such as developmental stenosis, may predispose to CSM. In addition to congenital cervical spinal stenosis, spontaneous fusion of the cervical vertebrae is a further type of congenital malformation that is also a known cause of CSM. ${ }^{4}$ Surgeries involving anterior and posterior approaches, including anterior cervical discectomy with fusion (ACDF), ${ }^{5-11}$ anterior cervical corpectomy with fusion (ACCF), ${ }^{6-8,10-13}$ laminoplasty, ${ }^{14-21}$ laminectomy, ${ }^{19,21-25}$ and laminectomy with fusion (class III), ${ }^{26-30}$ have been developed, and the functional outcome is improved after surgical treatment for CSM. ${ }^{31-35}$ The surgical choice of an anterior, posterior, or combined approach for CSM should be based on the location and extent of compressive pathology, previous surgery, and the presence of preoperative neck pain, as well as the patient's age and overall health conditions. ${ }^{36-38}$ Among the anterior approaches, ACCF has demonstrated relatively good fusion 
rates, ${ }^{39-41}$ but is associated with high morbidity of nonunion due to multiple graft-host interfaces, ${ }^{42-45}$ a higher incidence of complications including vertebral artery injury, ${ }^{36,46}$ dural tears, and cerebrospinal fluid leakage. ${ }^{47}$ ACDF is safe and effective for managing multilevel CSM, with a low prevalence of graft extrusion or migration; ${ }^{37,48}$ however, ACDF may have a high risk of incomplete decompression, limited visual exposure, and injury to the cord, as well as a high rate of pseudarthrosis secondary to an increase in the number of fusion surfaces. ${ }^{36,46,49}$ Therefore, to date, the decision to treat CSM, especially multilevel CSM, with ACDF or ACCF remains controversial. ${ }^{50}$ In the present study, we conducted a meta-analysis to quantitatively determine the efficacy of ACDF and ACCF in the treatment of multilevel CSM.

\section{Materials and methods}

We performed the meta-analysis according to Preferred Reporting Items for Systematic Reviews and Meta-Analyses ${ }^{51}$ and the recommendations of the Cochrane Collaboration. ${ }^{52}$

\section{Data source and search}

We searched and identified all published studies that compared the efficacy of ACDF and ACCF in the treatment of multilevel CSM. An extensive search of the literature was performed in Embase (1974 to July 2014), PubMed (1966 to July 2014) and the Cochrane Library, Biological Abstracts, Science Citation Index, Chinese BioMedical Literature Database, and China National Knowledge Infrastructure (1980 to July 2014). Medical Subject Headings were used to search in both the Chinese and English languages. We used the following keywords: cervical spondylotic myelopathy (CSM), anterior cervical discectomy and fusion (ACDF), anterior cervical corpectomy and fusion (ACCF). The full search strategy is available upon request from the corresponding authors. Relevant reviews and meta-analysis of surgeries in the treatment of CSM were also checked for inclusive studies.

\section{Study selection}

This meta-analysis included studies primarily evaluating the efficacy of ACDF and ACCF in the treatment of multilevel CSM. The bibliographies of the search results were independently reviewed by two authors (ZW and JD) to identify relevant articles that met the inclusion criteria (full text or abstract). The quality of the studies was independently assessed, and the level of agreement between them was recorded. The decision on whether to include an article was made by manual screening of titles and abstracts, followed by full-text screening by the same reviewers. If additional data or clarification were necessary, we contacted the study authors. Any disagreements between initial reviewers were resolved by discussion with another reviewer until agreement was reached.

\section{Data extraction}

The data were extracted independently by two reviewers (ZL and HX). Data for publication information (name of first author, year of publication), study information (sample size and distributions of age and sex), and the effect of ACDF and ACCF in the treatment of multilevel CSM were collected using standard data extraction forms. The preoperative and postoperative Japanese Orthopedic Association (JOA) score, operation time, blood loss, surgical complications, neurological recovery rate, reoperation rate, as well as the recovery rates and the arm pain visual analog scale (VAS) scores were checked and extracted by the other two reviewers (GL and XL). The recovery rate was determined by the following equation:

$$
\begin{aligned}
& \text { Neurological } \\
& \text { recovery rate }
\end{aligned}=\frac{\begin{array}{l}
\text { JOA score at follow-up }- \\
\text { preoperative JOA score }
\end{array}}{17-\text { preoperative JOA score }} \times 100 \%
$$

Disagreement was checked again by a third reviewer (DL). Exclusion criteria were combined surgery, non-controlled studies, follow-up less than 1 year, and CSM caused by ossification of the posterior longitudinal ligament.

\section{Statistical analysis}

All statistical analyses were performed using RevMan version 5 from the Cochrane Collaboration.

Odds ratios were calculated for binary outcomes and weighted mean differences for continuous outcomes, along with $95 \%$ confidence intervals. The pooled relative risks were combined by the Mantel-Haenszel method. The Peto method was used when there were trials with no events in one or both arms. ${ }^{52,53}$ Heterogeneity was evaluated using the $\chi^{2}$ test and $I^{2}$ statistics (considered significant when the $P$-value for $\chi^{2}$ test was $<0.10$ or $I^{2}$ was $>50 \%$ ). The level of significance was set at $P<0.05$. Fixed-effect models were applied unless statistical heterogeneity was significant, in which case random-effect models were used. We also assessed the probability of publication bias with funnel plots ${ }^{54}$ and the Egger's test. ${ }^{55}$ We investigated the influence of study design (randomized controlled trial or quasi-randomized controlled trial) and fixed levels (short or long segment fixation) on pooled estimates using subgroup analysis. 


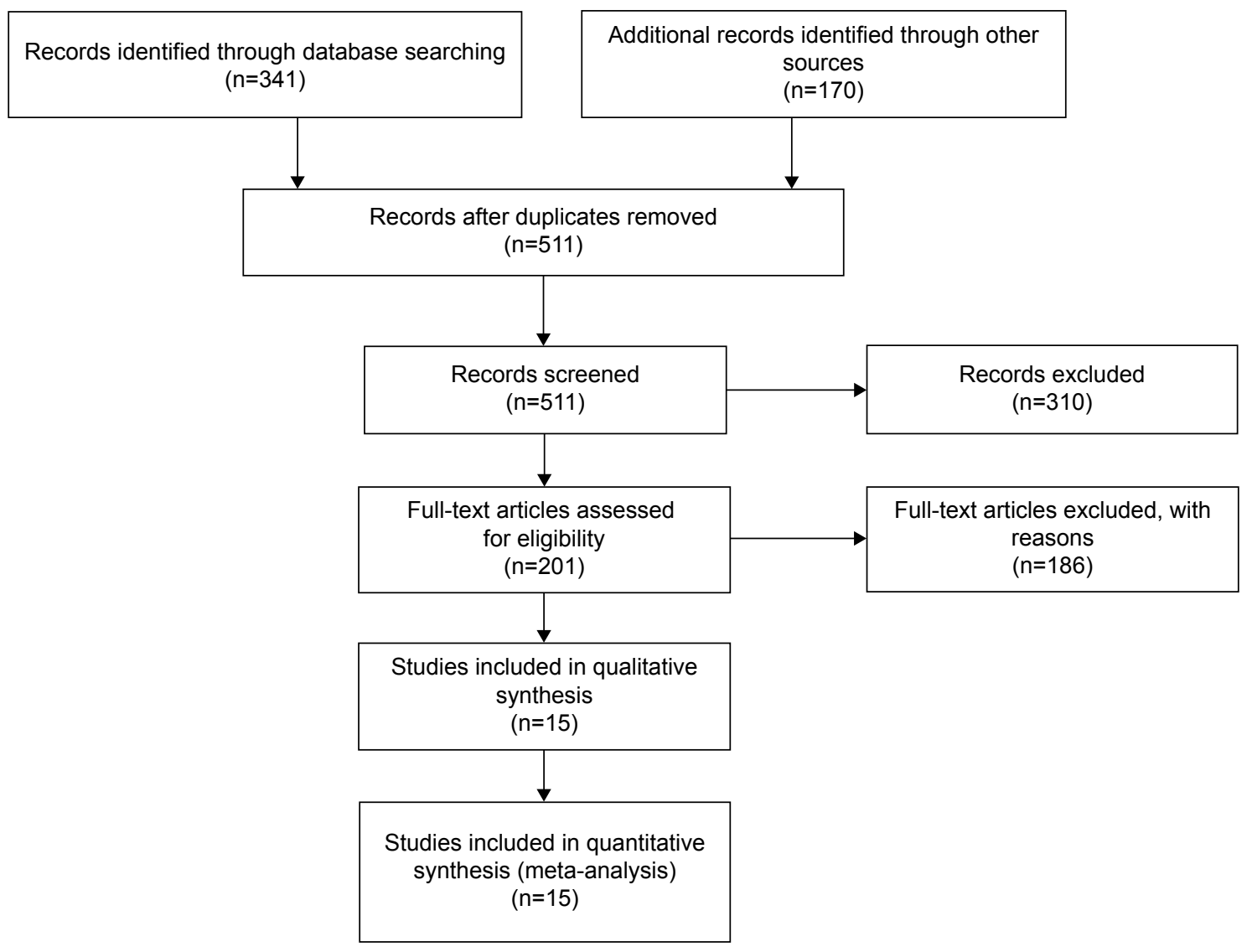

Figure I Flow chart of study selection.

\section{Results}

\section{Study selection and characteristics}

Five hundred and eleven relevant citations were selected for initial review according to the aforementioned search strategies and provided data regarding anterior cervical discectomy and corpectomy in patients with multilevel CSM.
Of these, 496 were initially excluded after reading the abstracts and/or whole articles (Figure 1). Finally, the systematic literature search generated a total of 15 datasets and 1,368 patients for meta-analysis. The demographic data from studies included in the meta-analysis are shown in Table 1.

Table I Demographic data from studies included in meta-analysis

\begin{tabular}{|c|c|c|c|c|}
\hline Study & Surgeries & Patients, n (ACDF/ACCF) & Country & Year of publication \\
\hline Li et $\mathrm{al}^{7}$ & ACDF/ACCF & $89(47 / 42)$ & People's Republic of China & 2013 \\
\hline Lin et $\mathrm{al}^{\prime \prime}$ & ACDF/ACCF & $120(57 / 63)$ & People's Republic of China & 2012 \\
\hline Liu et $\mathrm{al}^{8}$ & $\mathrm{ACDF} / \mathrm{ACCF}$ & $108(69 / 39)$ & People's Republic of China & 2012 \\
\hline Song et $\mathrm{al}^{10}$ & $\mathrm{ACDF} / \mathrm{ACCF}$ & $40(25 / 15)$ & South Korea & 2012 \\
\hline Guo et $\mathrm{al}^{58}$ & $\mathrm{ACDF} / \mathrm{ACCF}$ & $67(43 / 24)$ & People's Republic of China & 2011 \\
\hline Lian et $\mathrm{al}^{59}$ & $\mathrm{ACDF} / \mathrm{ACCF}$ & $105(55 / 50)$ & People's Republic of China & 2010 \\
\hline Oh et $\mathrm{a}^{49}$ & ACDF/ACCF & $31(14 / 17)$ & South Korea & 2009 \\
\hline Uribe et $a^{60}$ & $\mathrm{ACDF} / \mathrm{ACCF}$ & $80(42 / 38)$ & USA & 2009 \\
\hline Hwang et $\mathrm{al}^{41}$ & $\mathrm{ACDF} / \mathrm{ACCF}$ & $62(27 / 35)$ & People's Republic of China & 2007 \\
\hline Liu et al ${ }^{61}$ & $\mathrm{ACDF} / \mathrm{ACCF}$ & $52(19 / 33)$ & People's Republic of China & 2006 \\
\hline Nirala et $\mathrm{a}^{62}$ & $\mathrm{ACDF} / \mathrm{ACCF}$ & $201(69 / 132)$ & India & 2004 \\
\hline Hilibrand et al ${ }^{40}$ & $\mathrm{ACDF} / \mathrm{ACCF}$ & $190(131 / 59)$ & USA & 2002 \\
\hline Wang et a ${ }^{63}$ & $\mathrm{ACDF} / \mathrm{ACCF}$ & $52(32 / 20)$ & USA & 2001 \\
\hline Emery et a ${ }^{64}$ & $\mathrm{ACDF} / \mathrm{ACCF}$ & $100(45 / 55)$ & USA & 1998 \\
\hline Yonenobu et a $\left.\right|^{65}$ & ACDF/ACCF & $71(50 / 21)$ & Japan & 1985 \\
\hline
\end{tabular}

Abbreviations: ACCF, anterior cervical corpectomy and fusion; ACDF, anterior cervical discectomy and fusion. 


\section{Methodological quality of the studies}

Fifteen selected studies were evaluated to have high levels of methodological quality (more than six stars) according to the Newcastle-Ottawa quality assessment scale. ${ }^{56}$

\section{Comparison of operation time between ACDF and ACCF for CSM}

Seven studies with a total of 551 CSM patients who underwent either ACDF or ACCF surgery were meta-analyzed. Heterogeneity analysis shows that $I^{2}$ was $97 \%$. The test for overall effect $(Z=0.78, P=0.43)$ indicated that the operation time between ACDF and ACCF for CSM was not significantly different (Figure 2).

\section{Comparison of blood loss between ACDF and ACCF for CSM}

Seven studies reporting blood loss in a total of $551 \mathrm{CSM}$ patients who underwent ACDF or ACCF surgery were also meta-analyzed. Heterogeneity analysis showed that $I^{2}$ was $98 \%$. The test for overall effect $(Z=3.16, P=0.002)$ indicated that blood loss between ACDF and ACCF for CSM was significantly different (Figure 3).

\section{Comparison of bone fusion failure between ACDF and ACCF for CSM}

Fourteen studies including bone fusion failure records in a total of 1,297 CSM patients with ACDF or ACCF surgery were meta-analyzed. Heterogeneity analysis shows that $I^{2}$ was $78 \%$. The test for overall effect $(Z=0.8, P=0.42)$ indicated that bone fusion failure between the two types of surgery was not significantly different (Figure 4).

\section{Comparison of numbers of complications between ACDF and ACCF for CSM}

Ten studies with a record of numbers of complications during or after ACDF or ACCF surgery in a total of 906 CSM patients were meta-analyzed. Heterogeneity analysis shows that $I^{2}$ was $46 \%$. The test for overall effect $(Z=2.34, P=0.02$ ) indicated that numbers of complications between ACDF and ACCF for CSM was significantly different (Figure 5).

\section{Comparison of post JOA scores between ACDF and ACCF for CSM}

Nine studies with post JOA scores in a total of 674 CSM patients with ACDF or ACCF surgery were meta-analyzed. Heterogeneity analysis shows that $I^{2}$ was $88 \%$. The test for overall effect $(Z=0.45, P=0.66)$ indicated that post JOA scores between ACDF and ACCF for CSM were not significantly different (Figure 6).

\section{Comparison of clinical outcomes between ACDF and ACCF for CSM}

We determined the recovery rates for five studies in a total of 384 CSM patients with ACDF or ACCF surgery. Heterogeneity analysis shows that $I^{2}$ was $90 \%$. The test for overall effect $(Z=0.71, P=0.48)$ indicated that the recovery rates between ACDF and ACCF for CSM were not significantly different (Figure 7A). In addition, we also determined the

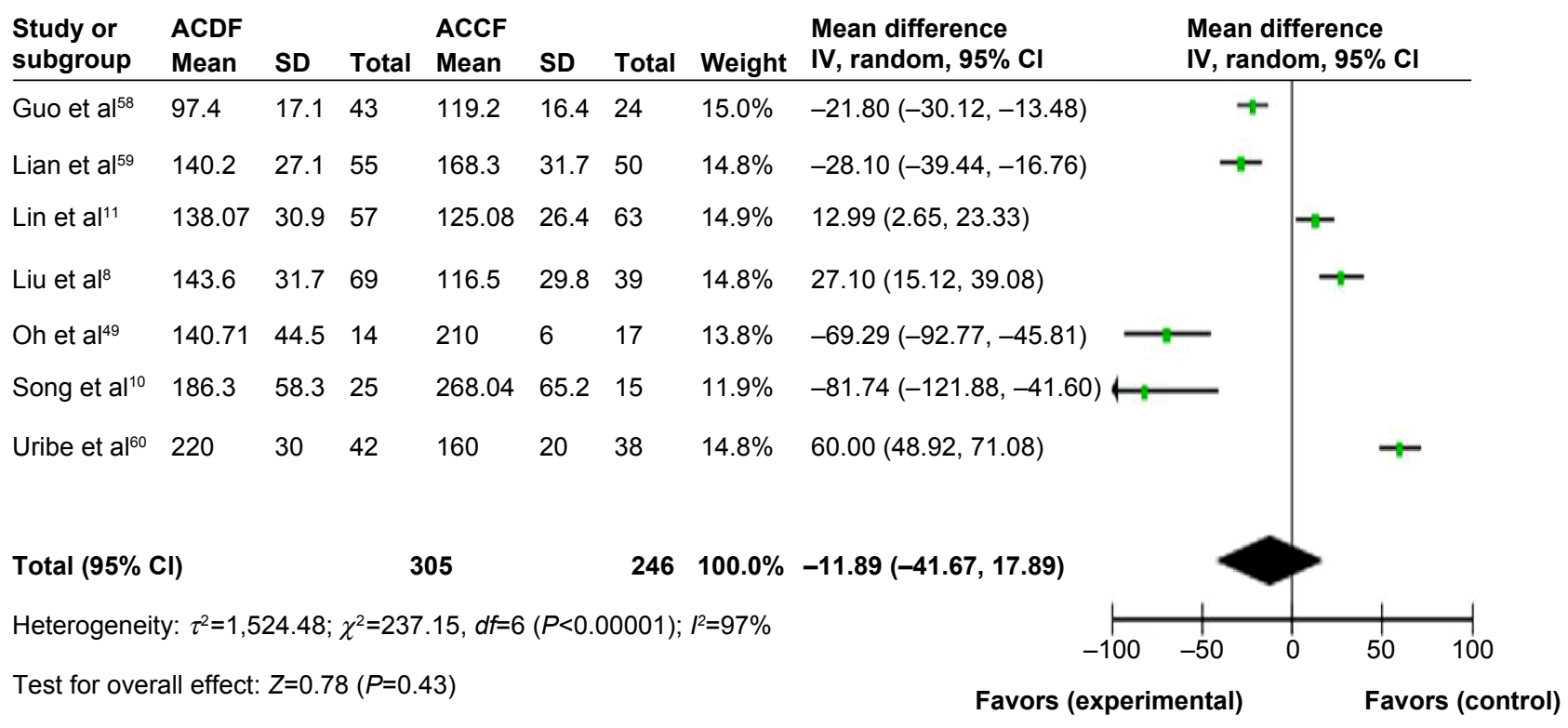

Figure 2 Comparison of operation time between ACDF and ACCF for the treatment of CSM.

Abbreviations: ACDF, anterior cervical discectomy and fusion; ACCF, anterior cervical corpectomy and fusion; CSM, cervical spondylotic myelopathy; Cl, confidence interval; SD, standard deviation; IV, independent variable. 


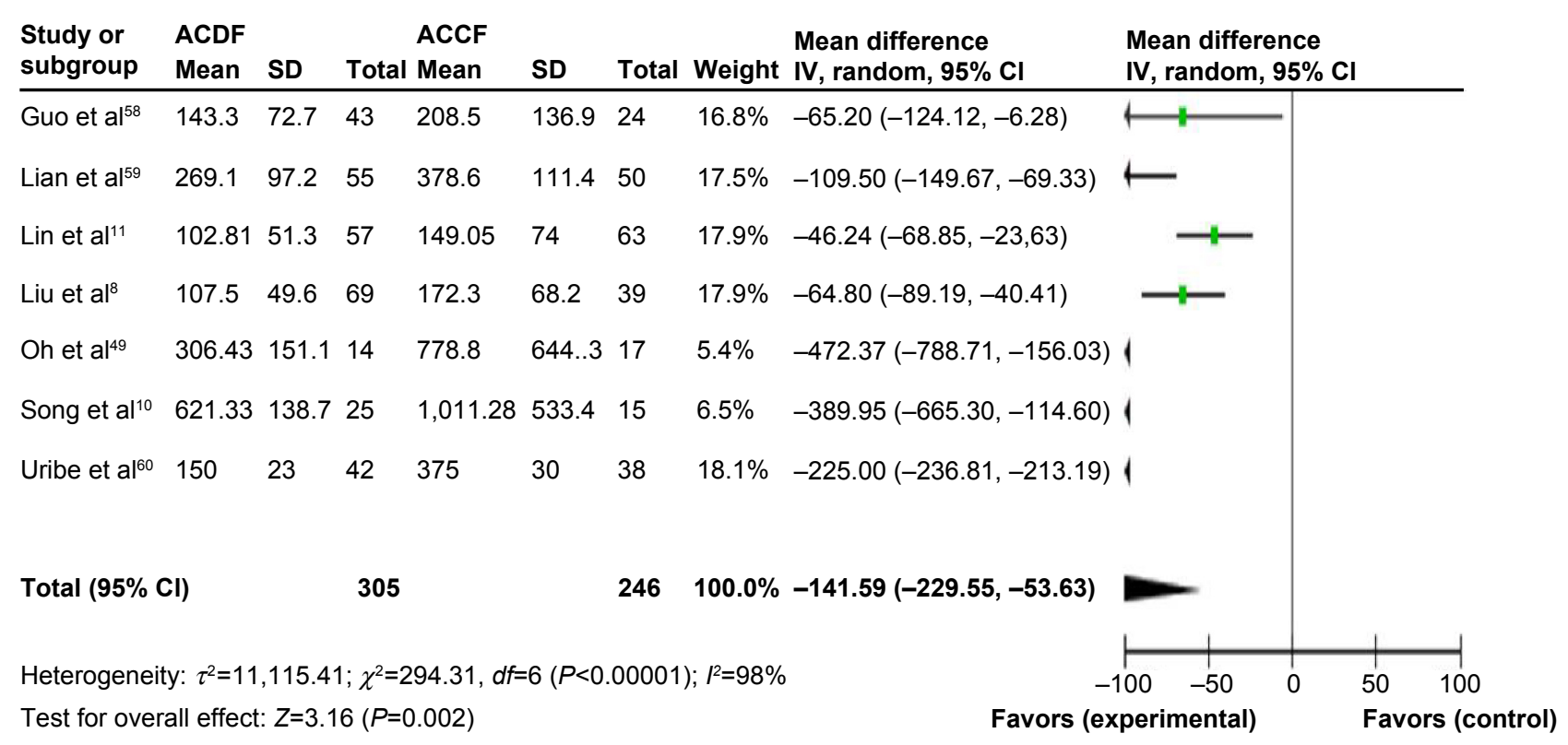

Figure 3 Comparison of blood loss between ACDF and ACCF for the treatment of CSM.

Abbreviations: ACDF, anterior cervical discectomy and fusion; ACCF, anterior cervical corpectomy and fusion; CSM, cervical spondylotic myelopathy; CI, confidence interval; SD, standard deviation; IV, independent variable.

VAS scores in four studies in a total of 236 CSM patients with ACDF or ACCF surgery. Heterogeneity analysis shows that $I^{2}$ was $76 \%$. The test for overall effect $(Z=1.05, P=0.29)$ indicated that the VAS scores between ACDF and ACCF for CSM was not significantly different (Figure 7B).

\section{Sensitivity analysis and publication bias}

A sensitivity analysis was conducted to assess the stability of our results. The pooled odds ratios or mean differences were not significantly changed, indicating the stability of our analyses. The funnel plots were largely symmetrical (Figure 8)

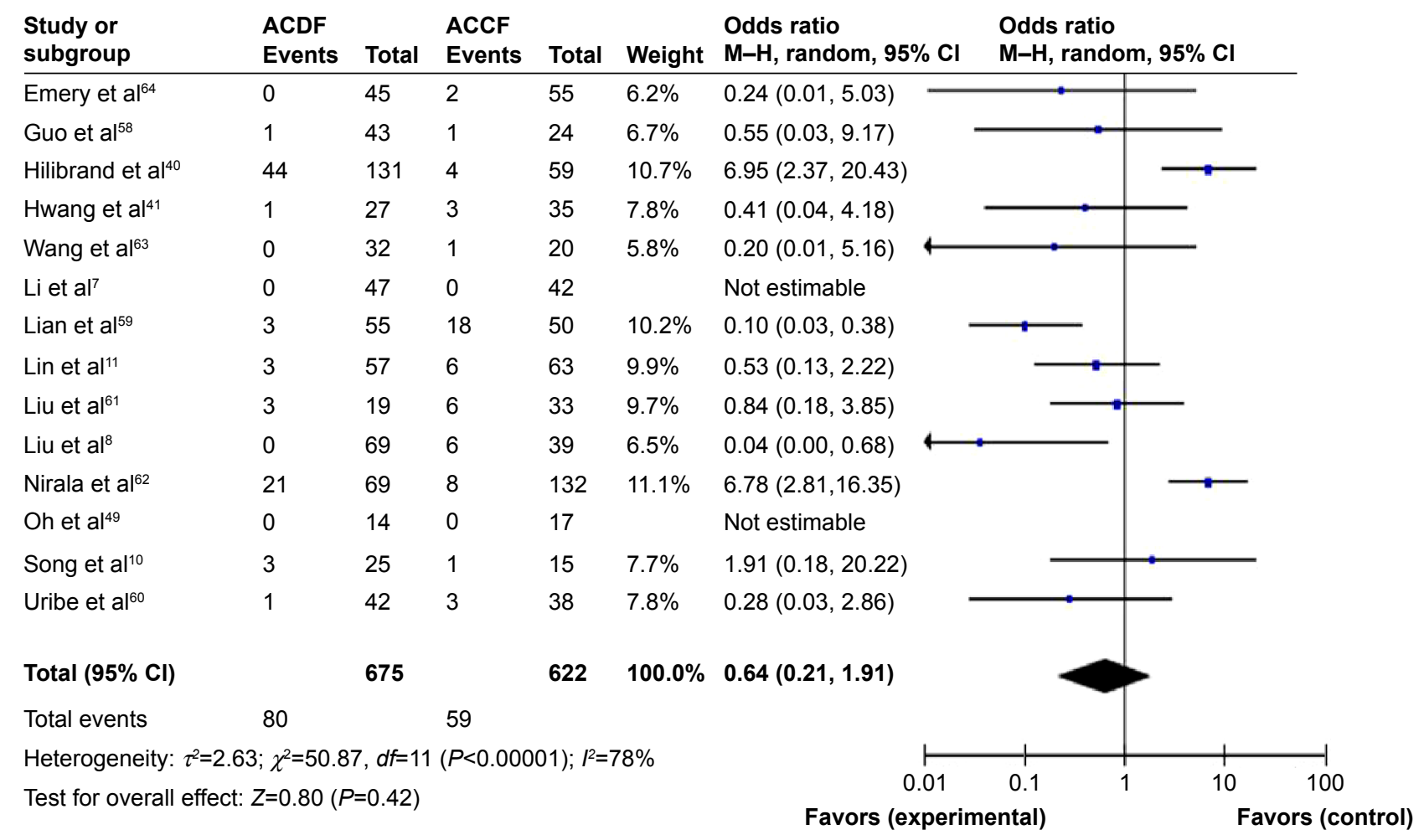

Figure 4 Comparison of bone fusion failure between ACDF and ACCF for the treatment of CSM.

Abbreviations: ACDF, anterior cervical discectomy and fusion; ACCF, anterior cervical corpectomy and fusion; CSM, cervical spondylotic myelopathy; Cl, confidence interval; $\mathrm{M}-\mathrm{H}$, Mantel-Haenszel test. 


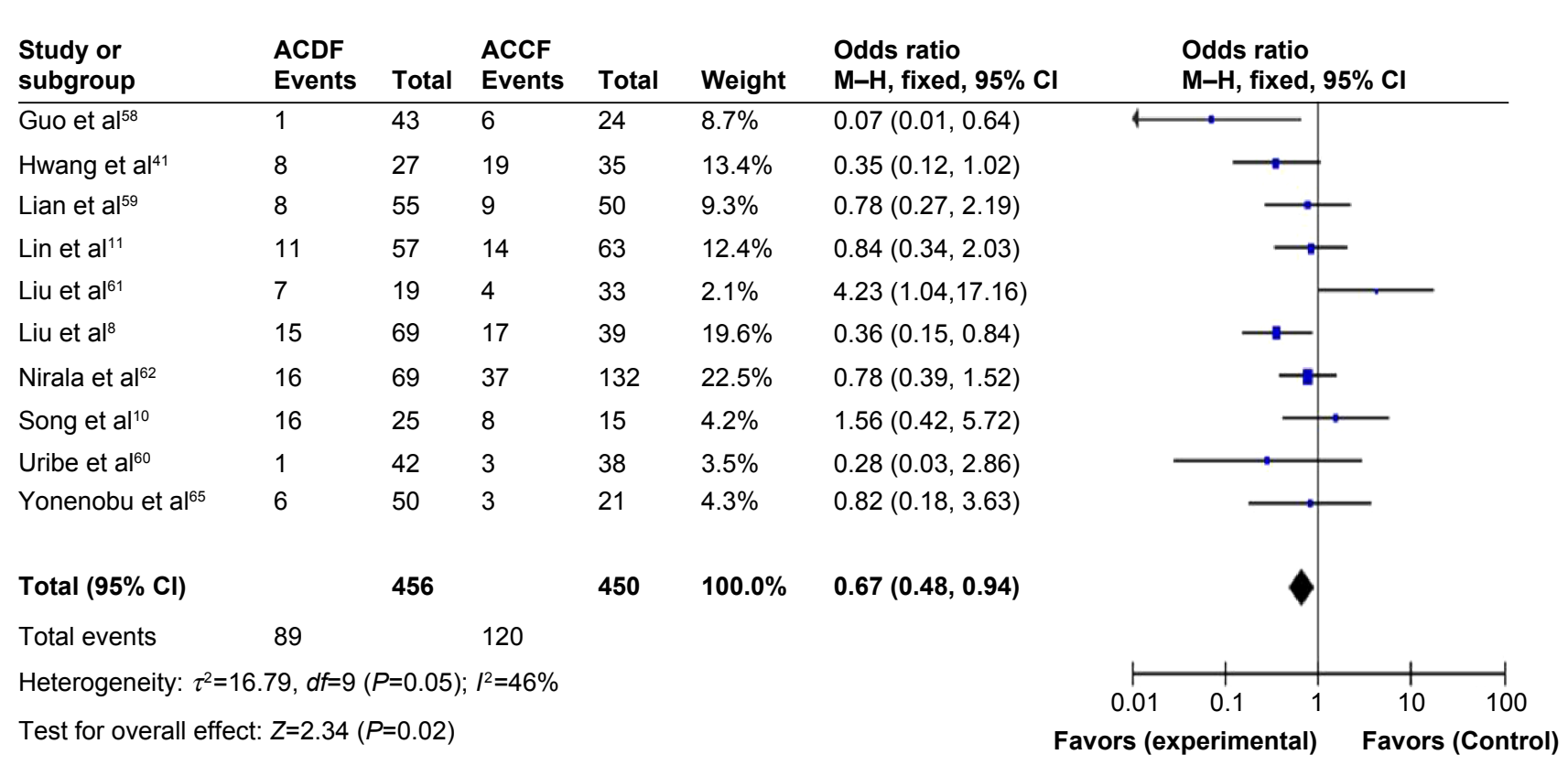

Figure 5 Comparison of numbers of complications between ACDF and ACCF for the treatment of CSM.

Abbreviations: ACDF, anterior cervical discectomy and fusion; ACCF, anterior cervical corpectomy and fusion; CSM, cervical spondylotic myelopathy; CI, confidence interval; M-H, Mantel-Haenszel test.

suggesting that there was no publication bias in the metaanalysis of CSM patients with ACDF or ACCF surgery.

\section{Discussion}

Previous studies have shown that surgical treatments of two-level CSM using ACDF or ACCF are similar in terms of clinical outcome. However, with regard to the amount of bleeding and radiological results, two-level ACDF was found to be superior to one-level ACCF in terms of operation times. ${ }^{49}$

Cunningham et al reviewed retrospective cohort studies comparing ACDF, corpectomy, laminoplasty, and

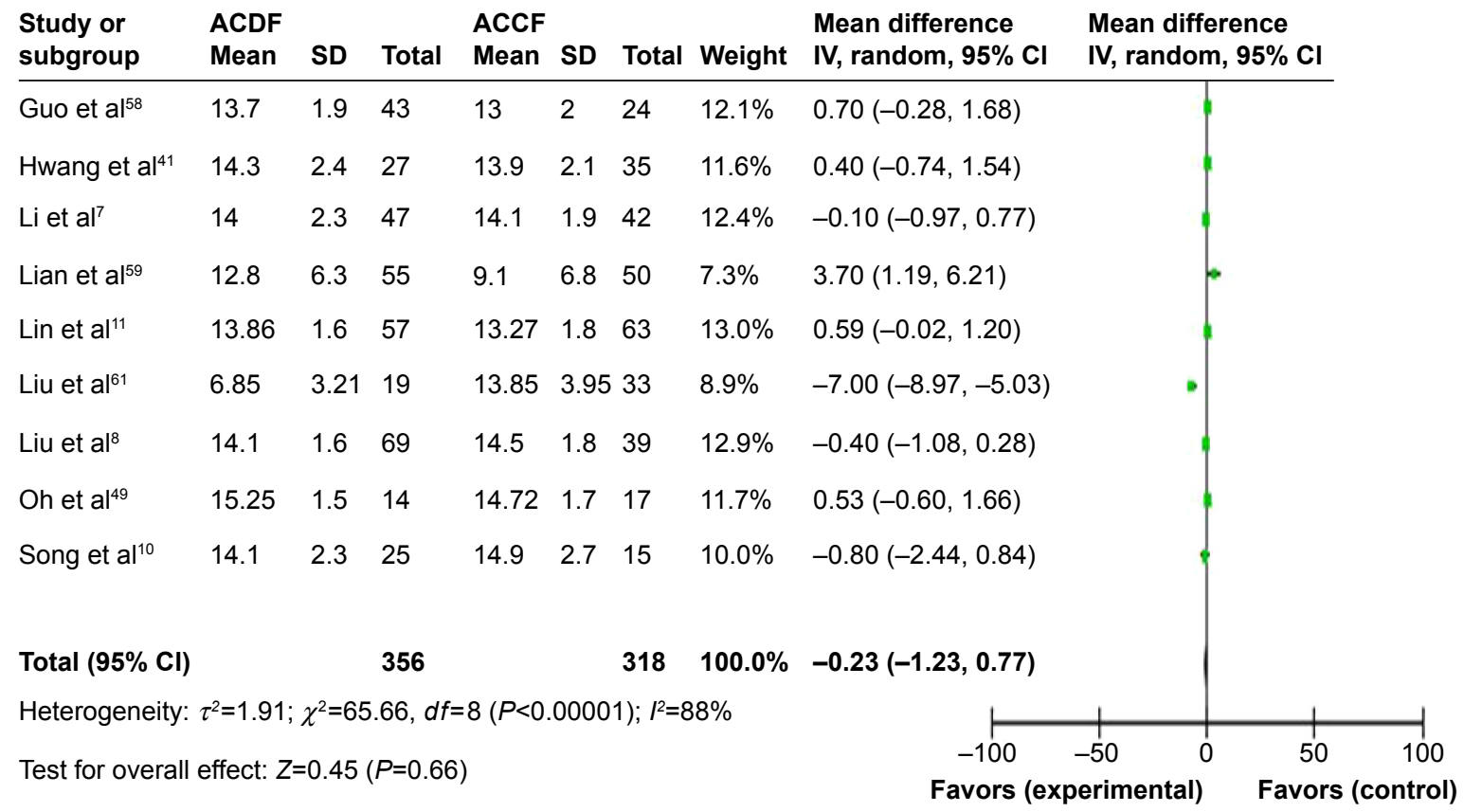

Figure 6 Comparison of post Japanese Orthopedic Association scores between ACDF and ACCF for the treatment of CSM.

Abbreviations: ACDF, anterior cervical discectomy and fusion; ACCF, anterior cervical corpectomy and fusion; CSM, cervical spondylotic myelopathy; IV, independent variable; $\mathrm{Cl}$, confidence interval; SD, standard deviation. 


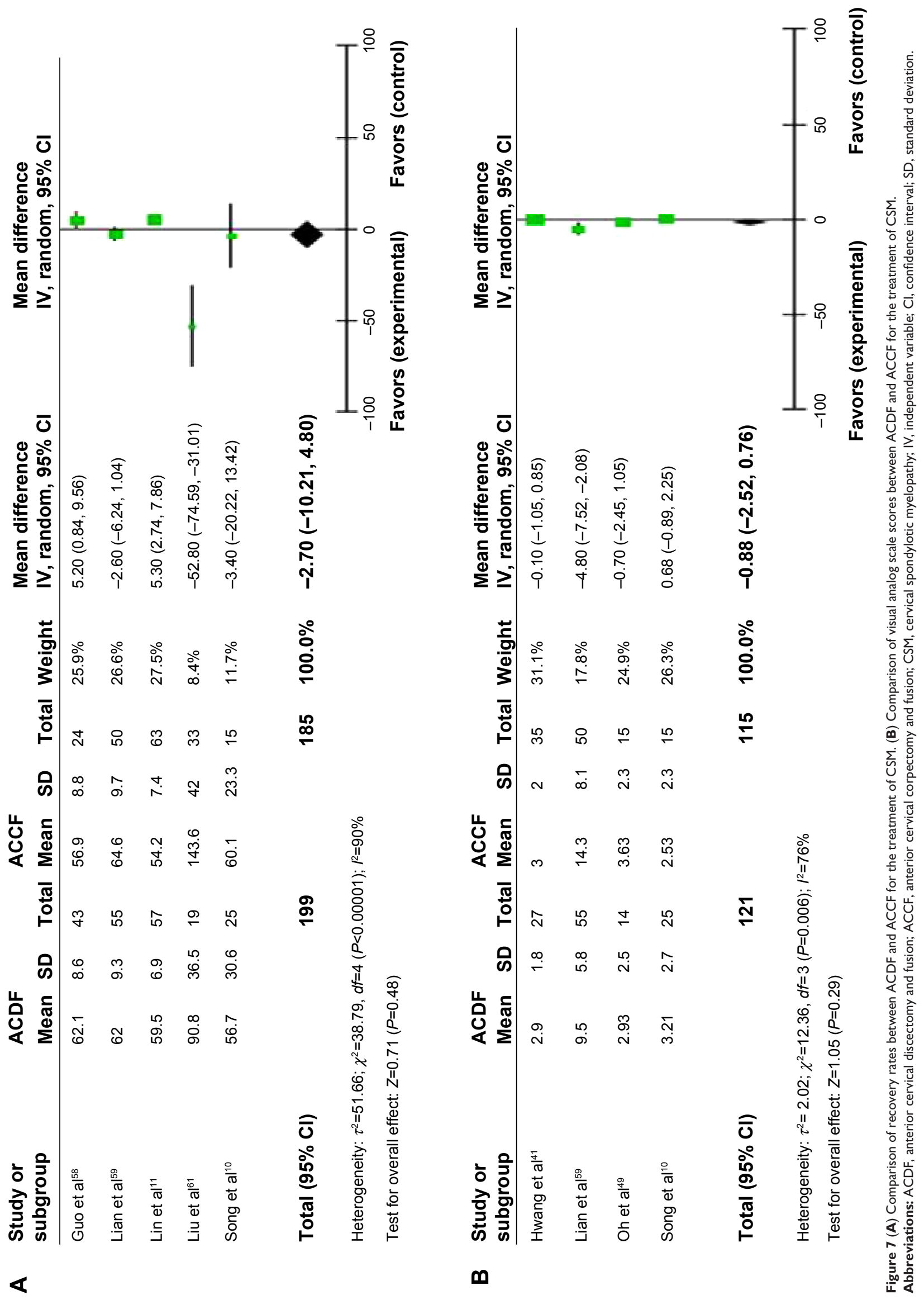


laminectomy and fusion as surgical options for CSM from 1980 to January 2008, and concluded that all approaches yield similar neurorecovery rates. ${ }^{57}$ Recently, Shamji et al reviewed studies comparing multiple discectomies with single or multiple corpectomy, multiple discectomies with a hybrid discectomy-corpectomy procedure, and multiple corpectomies with a hybrid discectomy-corpectomy procedure, and concluded that all three operative approaches are effective strategies for the anterior surgical management of CSM. ${ }^{1}$ However, which surgery is a better option in the treatment of multilevel CSM remains unclear.

Based on 15 studies and a total of 1,368 cases of multilevel CSM using ACDF or ACCF, this pooled analysis comprehensively assessed the clinical outcomes after surgery. Using pooled analysis from the included studies, we found that although blood loss and numbers of complications in ACDF was significantly less than in ACCF, other clinical outcomes, such as operation time, bone fusion failure, and post JOA scores between ACDF and ACCF for multilevel CSM were not significantly different.

We did find evidence of publication bias, and consistent results are shown in sensitivity analyses. We should mention several potential limitations of this study. First, the searching strategy was restricted to articles published in the English or Chinese languages. Articles with potentially high-quality data that were published in other languages were not included because of anticipated difficulties in obtaining accurate medical translations. Second, the possibility of information and selection biases and unidentified confounders cannot be completely excluded because all of the included studies were observational. Hence, caution is advised when interpreting our findings and how they may relate to the general population.

Based on this meta-analysis of ACDF and ACCF for the treatment of CSM, we conclude that although blood loss and numbers of complications during surgery in ACDF were
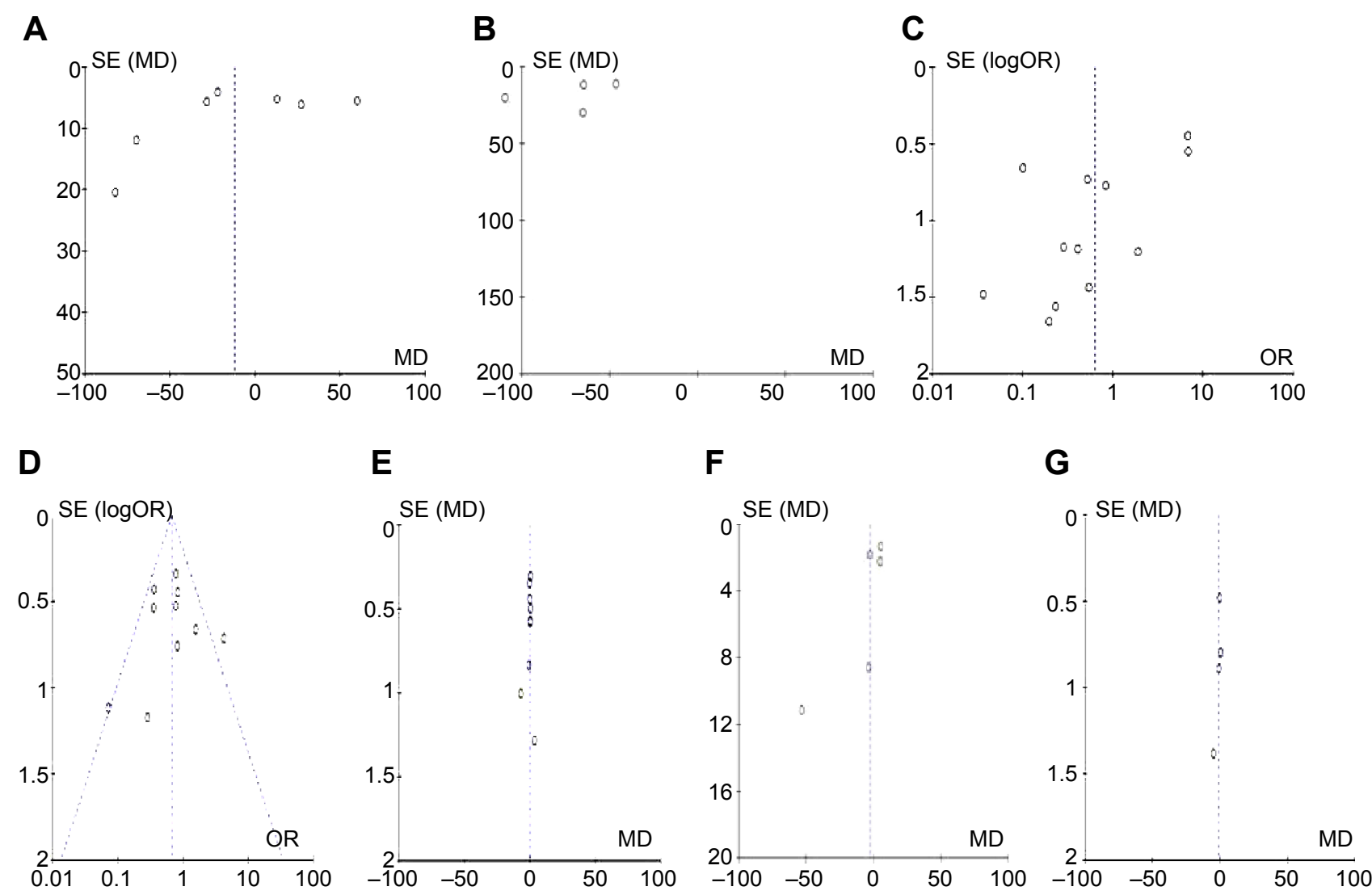

Figure $\mathbf{8}$ The funnel plots are largely symmetrical, suggesting there is no publication bias in the meta-analysis of anterior cervical discectomy and fusion and anterior cervical corpectomy and fusion in the treatment of cervical spondylotic myelopathy.

Notes: The funnel plot from seven studies comparing operation time (A). The funnel plot from seven studies comparing blood loss (B). The funnel plot from I4 studies comparing bone fusion failure (C). The funnel plot from ten studies comparing complications (D). The funnel plot from nine studies comparing post Japanese Orthopedic Association scores (E). The funnel plot from five studies comparing the recovery rates (F). The funnel plot from four studies comparing the visual analog scale scores $(\mathbf{G})$. Abbreviations: SE, standard error; MD, mean difference. 
significantly less that with ACCF, in terms of other clinical outcomes, such as operation time, bone fusion failure, post JOA scores, recovery rates, and VAS scores, there is no statistically significant difference between ACDF and ACCF for multilevel CSM were not significantly different.

\section{Disclosure}

The authors report no conflicts of interest in this work.

\section{References}

1. Shamji MF, Massicotte EM, Traynelis VC, Norvell DC, Hermsmeyer JT, Fehlings MG. Comparison of anterior surgical options for the treatment of multilevel cervical spondylotic myelopathy: a systematic review. Spine (Phila Pa 1976). 2013;38:S195-S209.

2. Kim HJ, Tetreault LA, Massicotte EM, et al. Differential diagnosis for cervical spondylotic myelopathy: literature review. Spine (Phila Pa 1976). 2013;38:S78-S88.

3. Toledano M, Bartleson JD. Cervical spondylotic myelopathy. Neurol Clin. 2013;31:287-305.

4. Eubanks JD, Belding J, Schnaser E, et al. Congenital stenosis and adjacent segment disease in the cervical spine. Orthopedics. 2013;36: e1251-e1255.

5. Ding C, Hong Y, Liu H, Shi R, Song Y, Li T. Comparison of cervical dise arthroplasty with anterior cervical discectomy and fusion for the treatment of cervical spondylotic myelopathy. Acta Orthop Belg. 2013;79: 338-346.

6. Burkhardt JK, Mannion AF, Marbacher S, et al. A comparative effectiveness study of patient-rated and radiographic outcome after 2 types of decompression with fusion for spondylotic myelopathy: anterior cervical discectomy versus corpectomy. Neurosurg Focus. 2013;35:E4.

7. Li J, Zheng Q, Guo X, et al. Anterior surgical options for the treatment of cervical spondylotic myelopathy in a long-term follow-up study. Arch Orthop Trauma Surg. 2013;133:745-751.

8. Liu Y, Hou Y, Yang L, et al. Comparison of 3 reconstructive techniques in the surgical management of multilevel cervical spondylotic myelopathy. Spine (Phila Pa 1976). 2012;37:E1450-E1458.

9. Basu S, Sreeramalingam R. Adjacent level spondylodiscitis after anterior cervical decompression and fusion. Indian J Orthop. 2012;46: $360-363$

10. Song KJ, Lee KB, Song JH. Efficacy of multilevel anterior cervical discectomy and fusion versus corpectomy and fusion for multilevel cervical spondylotic myelopathy: a minimum 5-year follow-up study. Eur Spine J. 2012;21:1551-1557.

11. Lin Q, Zhou X, Wang X, Cao P, Tsai N, Yuan W. A comparison of anterior cervical discectomy and corpectomy in patients with multilevel cervical spondylotic myelopathy. Eur Spine J. 2012;21:474-481.

12. Fengbin Y, Jinhao M, Xinyuan L, Xinwei W, Yu C, Deyu C. Evaluation of a new type of titanium mesh cage versus the traditional titanium mesh cage for single-level, anterior cervical corpectomy and fusion. Eur Spine J. 2013;3:3.

13. Gao R, Yang L, Chen H, Liu Y, Liang L, Yuan W. Long term results of anterior corpectomy and fusion for cervical spondylotic myelopathy. PLoS One. 2012;7:e34811

14. Miyamoto H, Maeno K, Uno K, Kakutani K, Nishida K, Sumi M. Outcomes of surgical intervention for cervical spondylotic myelopathy accompanying local kyphosis (comparison between laminoplasty alone and posterior reconstruction surgery using the screw-rod system). Eur Spine J. 2013;2:2.

15. Sah S, Wang L, Dahal M, Acharya P, Dwivedi R. Surgical management of cervical spondylotic myelopathy. JNMA J Nepal Med Assoc. 2012; 52:172-177.
16. Umeda M, Sasai K, Kushida T, et al. A less-invasive cervical laminoplasty for spondylotic myelopathy that preserves the semispinalis cervicis muscles and nuchal ligament. J Neurosurg Spine. 2013;18: 545-552.

17. Uehara M, Takahashi J, Ogihara N, et al. Cervical pedicle screw fixation combined with laminoplasty for cervical spondylotic myelopathy with instability. Asian Spine J. 2012;6:241-248.

18. Yang HL, Chen GD, Zhang HT, Wang L, Luo ZP. Open-door laminoplasty with plate fixation at alternating levels for treatment of multilevel degenerative cervical disease. J Spinal Disord Tech. 2013;26: E13-E18.

19. Kode S, Gandhi AA, Fredericks DC, Grosland NM, Smucker JD. Effect of multilevel open-door laminoplasty and laminectomy on flexibility of the cervical spine: an experimental investigation. Spine (Phila Pa 1976). 2012;37:E1165-E1170.

20. Mitsunaga LK, Klineberg EO, Gupta MC. Laminoplasty techniques for the treatment of multilevel cervical stenosis. Adv Orthop. 2012; 2012:307916.

21. Hardman J, Graf O, Kouloumberis PE, Gao WH, Chan M, Roitberg BZ. Clinical and functional outcomes of laminoplasty and laminectomy. Neurol Res. 2010;32:416-420.

22. Radcliff KE, Limthongkul W, Kepler CK, et al. Cervical laminectomy width and spinal cord drift are risk factors for postoperative C5 palsy. J Spinal Disord Tech. 2012;20:20.

23. Ryken TC, Heary RF, Matz PG, et al. Cervical laminectomy for the treatment of cervical degenerative myelopathy. J Neurosurg Spine. 2009; $11: 142-149$

24. Kristof RA, Kiefer T, Thudium M, et al. Comparison of ventral corpectomy and plate-screw-instrumented fusion with dorsal laminectomy and rod-screw-instrumented fusion for treatment of at least two vertebral-level spondylotic cervical myelopathy. Eur Spine $J$. 2009;18:1951-1956.

25. Otani K, Sato K, Yabuki S, Iwabuchi M, Kikuchi S. A segmental partial laminectomy for cervical spondylotic myelopathy: anatomical basis and clinical outcome in comparison with expansive open-door laminoplasty. Spine (Phila Pa 1976). 2009;34:268-273.

26. Shunzhi Y, Zhonghai L, Fengning L, Zhi C, Tiesheng H. Surgical management of 4-level cervical spondylotic myelopathy. Orthopedics. 2013;36:e613-e620.

27. Zhang H, Sun T, Lu S, Li Q, Yadav SK. [Comparison of effectiveness between laminoplasty and laminectomy decompression and fusion with internal fixation for cervical spondylotic myelopathy]. Zhongguo Xiu Fu Chong Jian Wai Ke Za Zhi. 2012;26:1191-1196. Chinese.

28. Woods BI, Hohl J, Lee J, Donaldson W 3rd, Kang J. Laminoplasty versus laminectomy and fusion for multilevel cervical spondylotic myelopathy. Clin Orthop Relat Res. 2011;469:688-695.

29. Anderson PA, Matz PG, Groff MW, et al. Laminectomy and fusion for the treatment of cervical degenerative myelopathy. J Neurosurg Spine. 2009;11:150-156.

30. Gok B, McLoughlin GS, Sciubba DM, et al. Surgical management of cervical spondylotic myelopathy with laminectomy and instrumented fusion. Neurol Res. 2009;31:1097-1101.

31. Lebl DR, Hughes A, Cammisa FP Jr, O'Leary PF. Cervical spondylotic myelopathy: pathophysiology, clinical presentation, and treatment. HSS J. 2011;7:170-178

32. Lawrence BD, Shamji MF, Traynelis VC, et al. Surgical management of degenerative cervical myelopathy: a consensus statement. Spine (Phila Pa 1976). 2013;38:S171-S172.

33. Lawrence BD, Jacobs WB, Norvell DC, Hermsmeyer JT, Chapman JR, Brodke DS. Anterior versus posterior approach for treatment of cervical spondylotic myelopathy: a systematic review. Spine (Phila Pa 1976). 2013;38:S173-S182.

34. Muthukumar N. Surgical management of cervical spondylotic myelopathy. Neurol India. 2012;60:201-209.

35. Lawrence BD, Brodke DS. Posterior surgery for cervical myelopathy: indications, techniques, and outcomes. Orthop Clin North Am. 2012;43: 29-40, vii-viii. 
36. Rao RD, Gourab K, David KS. Operative treatment of cervical spondylotic myelopathy. J Bone Joint Surg Am. 2006;88:1619-1640.

37. Hillard VH, Apfelbaum RI. Surgical management of cervical myelopathy: indications and techniques for multilevel cervical discectomy. Spine J. 2006;6:242S-251S.

38. Traynelis VC, Arnold PM, Fourney DR, Bransford RJ, Fischer DJ, Skelly AC. Alternative procedures for the treatment of cervical spondylotic myelopathy: arthroplasty, oblique corpectomy, skip laminectomy: evaluation of comparative effectiveness and safety. Spine (Phila Pa 1976). September 10, 2013. [Epub ahead of print].

39. Gore DR. The arthrodesis rate in multilevel anterior cervical fusions using autogenous fibula. Spine (Phila Pa 1976). 2001;26:1259-1263.

40. Hilibrand AS, Fye MA, Emery SE, Palumbo MA, Bohlman HH. Increased rate of arthrodesis with strut grafting after multilevel anterior cervical decompression. Spine (Phila Pa 1976). 2002;27:146-151.

41. Hwang SL, Lee KS, Su YF, et al. Anterior corpectomy with iliac bone fusion or discectomy with interbody titanium cage fusion for multilevel cervical degenerated disc disease. J Spinal Disord Tech. 2007;20: 565-570.

42. Swank ML, Lowery GL, Bhat AL, McDonough RF. Anterior cervical allograft arthrodesis and instrumentation: multilevel interbody grafting or strut graft reconstruction. Eur Spine J. 1997;6:138-143.

43. Bolesta MJ, Rechtine GR 2nd, Chrin AM. Three- and four-level anterior cervical discectomy and fusion with plate fixation: a prospective study. Spine (Phila Pa 1976). 2000;25:2040-2044.

44. Wang JC, McDonough PW, Kanim LE, Endow KK, Delamarter RB. Increased fusion rates with cervical plating for three-level anterior cervical discectomy and fusion. Spine (Phila Pa 1976). 2001;26:643-646.

45. Fraser JF, Hartl R. Anterior approaches to fusion of the cervical spine: a meta-analysis of fusion rates. J Neurosurg Spine. 2007;6:298-303.

46. Iwasaki M, Kawaguchi Y, Kimura T, Yonenobu K. Long-term results of expansive laminoplasty for ossification of the posterior longitudinal ligament of the cervical spine: more than 10 years follow up. J Neurosurg. 2002;96:180-189.

47. Cloward RB. The anterior approach for removal of ruptured cervical disks. 1958. J Neurosurg Spine. 2007;6:496-511.

48. Chang SW, Kakarla UK, Maughan PH, et al. Four-level anterior cervical discectomy and fusion with plate fixation: radiographic and clinical results. Neurosurgery. 2010;66:639-646.

49. Oh MC, Zhang HY, Park JY, Kim KS. Two-level anterior cervical discectomy versus one-level corpectomy in cervical spondylotic myelopathy. Spine (Phila Pa 1976). 2009;34:692-696.

50. Han YC, Liu ZQ, Wang SJ, Li LJ, Tan J. Is anterior cervical discectomy and fusion superior to corpectomy and fusion for treatment of multilevel cervical spondylotic myelopathy? A systemic review and meta-analysis. PLoS One. 2014;9:e87191.

51. Moher D, Liberati A, Tetzlaff J, Altman DG. Reprint - preferred reporting items for systematic reviews and meta-analyses: the PRISMA statement. Phys Ther. 2009;89:873-880.
52. Bero L, Rennie D. The Cochrane Collaboration. Preparing, maintaining, and disseminating systematic reviews of the effects of health care. JAMA. 1995;274:1935-1938.

53. Higgins JPT, Green S. Cochrane handbook for systematic reviews of interventions version 5.0.2 (updated September 2009). The Cochrane Collaboration, 2009-2010; Accessed March 1.

54. Begg CB, Mazumdar M. Operating characteristics of a rank correlation test for publication bias. Biometrics. 1994;50:1088-1101.

55. Egger M, Davey Smith G, Schneider M, Minder C. Bias in meta-analysis detected by a simple, graphical test. BMJ. 1997;315:629-634.

56. Stang A. Critical evaluation of the Newcastle-Ottawa scale for the assessment of the quality of nonrandomized studies in meta-analyses. Eur J Epidemiol. 2010;25:603-605.

57. Cunningham MR, Hershman S, Bendo J. Systematic review of cohort studies comparing surgical treatments for cervical spondylotic myelopathy. Spine (Phila Pa 1976). 2010;35:537-543.

58. Guo Q, Bi X, Ni B, et al. Outcomes of three anterior decompression and fusion techniques in the treatment of three-level cervical spondylosis. Eur Spine J. 2011;20:1539-1544.

59. Lian XF, Xu JG, Zeng BF, Zhou W, Kong WQ, Hou TS. Noncontiguous anterior decompression and fusion for multilevel cervical spondylotic myelopathy: a prospective randomized control clinical study. Eur Spine J. 2010;19:713-719.

60. Uribe JS, Sangala JR, Duckworth EA, Vale FL. Comparison between anterior cervical discectomy fusion and cervical corpectomy fusion using titanium cages for reconstruction: analysis of outcome and longterm follow-up. Eur Spine J. 2009;18:654-662.

61. Liu P, Zhao J, Li Q. [A comparative research of multilevel cervical spondylotic myelopathy treated by two different anterior operative methods]. Zhongguo Xiu Fu Chong Jian Wai Ke Za Zhi. 2006;20: 362-366. Chinese.

62. Nirala AP, Husain M, Vatsal DK. A retrospective study of multiple interbody grafting and long segment strut grafting following multilevel anterior cervical decompression. Br J Neurosurg. 2004;18:227-232.

63. Wang JC, McDonough PW, Endow KK, Delamarter RB. A comparison of fusion rates between single-level cervical corpectomy and two-level discectomy and fusion. J Spinal Disord. 2001;14:222-225.

64. Emery SE, Bohlman HH, Bolesta MJ, Jones PK. Anterior cervical decompression and arthrodesis for the treatment of cervical spondylotic myelopathy. Two to seventeen-year follow-up. J Bone Joint Surg Am. 1998;80:941-951.

65. Yonenobu K, Fuji T, Ono K, Okada K, Yamamoto T, Harada N. Choice of surgical treatment for multisegmental cervical spondylotic myelopathy. Spine (Phila Pa 1976). 1985;10:710-716.
Therapeutics and Clinical Risk Management

\section{Publish your work in this journal}

Therapeutics and Clinical Risk Management is an international, peerreviewed journal of clinical therapeutics and risk management, focusing on concise rapid reporting of clinical studies in all therapeutic areas, outcomes, safety, and programs for the effective, safe, and sustained use of medicines. This journal is indexed on PubMed Central, CAS,
Dovepress

EMBase, Scopus and the Elsevier Bibliographic databases. The manuscript management system is completely online and includes a very quick and fair peer-review system, which is all easy to use. Visit http://www.dovepress.com/testimonials.php to read real quotes from published authors. 